\title{
El PERFormanCE AL JUSTO JUEZ SE APROPIA DEL ESPACIO. TEATRALIDAD, RELIGIOSIDAD Y ESTÉTICA EN UN LUGAR SAgrado de SAN Cristóbal de las Casas, Chiapas
}

\author{
The Performance to the Righteous Judge Takes over \\ Space. Theatricality, Religiosity and Aesthetics in a \\ Sacred Place of San Cristóbal de las Casas, Chiapas
}

\author{
Ricardo López Crocker* \\ doi: https://doi.org/10.31644/ED.V8.N2.2021.A03
}

\begin{abstract}
Resumen: Este artículo explora vínculos entre la teatralidad y la religiosidad para mostrar que los ritos al Justo Juez — prácticas performativas que serían consideradas extra-cotidianas por Barba (1992) - construyen un lugar antropológico de carácter sagrado en la capilla dedicada a esta advocación de Jesús en iglesia de La Merced de San Cristóbal de Las Casas, Chiapas. Se funda en una investigación etnográfica que permite analizar la configuración de un espacio social a través de sus prácticas performativas. Por último, pretende contribuir al ámbito epistemológico de los estudios sociales incorporando una perspectiva escénica.
\end{abstract}

Palabras clave: performance, lugar antropológico, teatralidad, religiosidad, imagen del Justo Juez.

\begin{abstract}
This article explores links between theatricality and religiousness to show that the rites to the Just Judge - performative practices that would be considered extra-everyday by Barba (1992) — build an anthropological place of a sacred character in the chapel dedicated to this invocation of Jesus in the church of La Merced de San Cristóbal de Las Casas, Chiapas. It is based on an ethnographic research that helps analyze the configuration of a social space through its performative practices. Finally, it aims to contribute to the epistemological field of social studies by incorporating a scenic perspective.
\end{abstract}

Keywords: performance, anthropological place, theatricality, religiosity, image of the Righteous Judge.

\footnotetext{
* Mtro. en Estudios sobre Diversidad Cultural y Espacios Sociales, Doctorante en Ciencias Sociales y Humanísticas, Centro de Estudios Superiores de México y Centroamérica, Universidad de Ciencias y Artes de Chiapas, México. Investigador y director de escena independiente. Correo-e: ricardo.lopez@e.unicach.mx; ricarcrocker@hotmail.com.

Fecha de recepción: 22/09/2020. Fecha de aceptación: 26/05/2021. Fecha de publicación: 30/07/2021.

(cc) BY-NC-ND
}

EntreDiversidades. Revista de Ciencias Sociales y Humanidades, Vol. 8, Núm. 2 (17), julio-diciembre 2021. Páginas: 56-76 ISSN-e: 2007-7610. https://doi.org/10.31644/ED.V8.N2.2021.A03 


\section{Introducción}

Este artículo es producto de la investigación realizada en el santuario del Justo Juez de la iglesia de La Merced de San Cristóbal de Las Casas, Chiapas. ${ }^{1}$ Empleé una metodología cualitativa, basada primordialmente en la observación directa de las prácticas de religiosidad acontecidas en este recinto durante el periodo comprendido de enero a junio de 2018; el trabajo de observación se complementó con charlas informales y entrevistas semi estructuradas a diversos actores de este espacio.

Para registrar y analizar las prácticas desde una perspectiva escénica, me ubiqué en el lugar actuando como un creyente más, estrategia que permitió presenciarlas desde todas las distancias y ángulos, interfiriendo lo menos posible en ellas con mi presencia. Observé, registré y analicé los ritos desde una perspectiva teatral, situando metafóricamente a la capilla del Justo Juez como un escenario. Por ello, el presente texto está construido desde esta mirada escénica, ubicándome como partícipe y espectador del performance, razón por la que expongo algunos pasajes desde mi experiencia vivida, los cuales están redactados en primera persona y tiempo presente.

Con base en estas observaciones planteo una discusión teórica articulando los conceptos de heterotopía (Foucault, 1984), lugar antropológico (Augé , 1995; Vergara, 2013), las regiones de la actuación en la vida cotidiana (Goffman, 1959) y la extra-cotidianidad (Barba, 1992) para exponer la forma en que el culto al Justo Juez y sus performances configuran un lugar antropológico de carácter sagrado.

Así, el culto de esta advocación es visto como reflejo de la ciudad heterotópica en la que sucede, de los cambios que en ella se gestan y que hacen posible la existencia de una dimensión estética en sus performances. Se expone cómo el culto al Justo Juez se apropia del espacio, haciendo que distintos imaginarios, tiempos y lenguajes se encuentren y confluyan en este lugar. De esta manera, el texto muestra cómo en San Cristóbal de Las Casas la religiosidad y la teatralidad tienen un importante punto de encuentro en la performatividad de los ritos, en su carácter escénico.

\section{El Justo Juez de la iglesia de La Merced}

La iglesia de La Merced es una de las más antiguas de San Cristóbal de Las Casas; su fundación original por los religiosos de la orden mercedaria data de $1537 .^{2}$ Forma parte de un complejo arquitectónico constituido por tres edificios articulados entre sí: el ex convento de La Merced, la iglesia homónima y la iglesia de El Calvario. Este complejo arquitectónico se ubica en el barrio de La Merced, en el centro de la ciudad, uno de los más visitados por turistas, ya que en él se encuentran dos importantes museos, así como numerosos hoteles y restaurantes.

\footnotetext{
${ }^{1}$ El performance al Justo Juez de la iglesia de La Merced, San Cristóbal de Las Casas, Chiapas, presentada para obtener el grado de Maestro en Estudios sobre Diversidad Cultural y Espacios Sociales, Instituto de Estudios Indígenas, Universidad Autónoma de Chiapas. Agradezco a Anna María Garza Caligaris su valiosa asesoría en la realización de esta investigación.

${ }^{2}$ María del Carmen León aporta la fecha de inicio de la congregación mercedaria y su iglesia en San Cristóbal de Las Casas, situándola en 1537 ya en su actual ubicación, como casa subsidiaria de la Orden de La Merced que se encontraba en Guatemala (León, 2004: 53-54).
}

EntreDiversidades. Revista de Ciencias Sociales y Humanidades, Vol. 8, Núm. 2 (17), julio-diciembre 2021. Páginas: 56-76 ISSN-e: 2007-7610. https://doi.org/10.31644/ED.V8.N2.2021.A03 
Como su nombre lo indica, esta iglesia está dedicada a la Virgen de La Merced, patrona del barrio y una de las imágenes más veneradas de la ciudad. También alberga el santuario del Justo Juez, el cual se compone de dos capillas, como se describirá más adelante.

El Justo Juez es una advocación de Jesucristo, inspirada en el momento bíblico en que Jesús fue presentado ante Poncio Pilatos para ser juzgado. Su imagen, la que se encuentra en la iglesia de La Merced, es una escultura en madera de tamaño "natural" (aproximadamente del tamaño de un hombre de baja estatura), articulada. Este no luce, como en la mayor parte de las imágenes que lo representan, crucificado o en predicación, sino que aparece sentado en un trono, apoyado en los reposabrazos con las palmas de las manos hacia arriba. Su torso y cabeza están en posición erguida y frontal, con la mirada firme enfocada en el horizonte. Sus rasgos son afilados, proyectando cierta severidad; su mirada es serena y neutral, como corresponde a su carácter de juez ecuánime y justo.

\section{Performatividad y religiosidad}

Performance y performatividad son términos estrechamente relacionados, ya que ambos son derivaciones de to perform (actuar, ejecutar, realizar); Erika Fischer-Lichte (2014) señala que la performatividad conduce al performance, a la realización escénica, por lo que "la realización escénica es la esencia de lo performativo" (Fischer-Lichte, 2014: 59). Así, la teatralidad está presente en la ritualidad desde su dimensión performativa. Durante el auge racionalista del siglo XIX la estética del teatro se legitimaba en la dramaturgia, sin embargo, en el tránsito al siglo XX las vanguardias artísticas produjeron una ruptura con esta idea, trasladando el "arte del teatro" a la puesta en escena.

Paralelamente, en un sentido similar, en el siglo XIX existía en los estudios religiosos una idea de superioridad del discurso sobre la práctica, del mito por sobre el rito. Esta relación también cambió durante el siglo XX. A partir de entonces, una inversión terminológica de la jerarquía ha prevalecido; los estudios religiosos se han centrado en el ritual y los estudios teatrales en la puesta en escena (Fischer-Lichte, 2014: 61-62).

Este acento en la performatividad de las prácticas permite observar diversas manifestaciones como realizaciones escénicas, en las que la actividad el ejecutante y la percepción del espectador hacen posible la generación de una experiencia estética, misma que en la teatralidad se refiere a lo que acontece en el transcurrir de la realización escénica (Fischer-Lichte, 2014: 45-57).

La experiencia estética en la realización escénica es autorreferencial, ya que solo ocurre en el acontecimiento, cobrando materialidad. De la misma manera, también lo es la experiencia religiosa, pues únicamente puede existir en el "círculo sagrado" en el que sucede y que se forma en el hacer e interactuar con el otro, en este caso, con el ser divino.

Al lugar donde sucede un hecho escénico se le considera un espacio performativo, el cual se constituye del espacio geométrico y el acontecer de actores y espectadores (Fischer-Lichte, 2014: 220). Por tanto, aunque los espacios teatrales son siempre performativos, hay otros que también pueden serlo en ciertas condiciones y momentos, como es el caso del lugar sagrado. Verlo como escenario teatral permite observar, describir y analizar su carácter complejo y heterotópico; y

EntreDiversidades. Revista de Ciencias Sociales y Humanidades, Vol. 8, Núm. 2 (17), julio-diciembre 2021. Páginas: 56-76 ISSN-e: 2007-7610. https://doi.org/10.31644/ED.V8.N2.2021.A03 
mostrar, además, la forma en que las prácticas performativas construyen el espacio, dándole sentido. Así, desde esta mirada, la espacialidad en la perspectiva escénica es de gran importancia.

En el texto se presenta al santuario del Justo Juez como un lugar sacro performativo en el que las prácticas institucionales y populares confluyen, se amalgaman, se abigarran. La exposición se divide en dos apartados: en el primero, el culto al Justo Juez es descrito como un lugar sagrado heterotópico (Foucault, 1984), en el que distintos lenguajes e imaginarios se encuentran e interactúan; en el segundo apartado se discuten y articulan los conceptos teóricos con los encuentros en campo, para explicar cómo el culto al Justo Juez y sus performances configuran este espacio sagrado.

\section{El lugar sagrado heterotópico}

Lo unico que se necesita para hacer teatro es un espacio vacio... y actores que lo llenen.

Peter Brook (1968)

La perspectiva teatral de este estudio, desde la que se ve al santuario del Justo Juez de la iglesia de La Merced de San Cristóbal de las Casas, Chiapas, como un escenario, me sitúa en un lugar heterotópico. Entendido como una heterotopía, como un lugar imposible, utópico y situado, el teatro resulta, además, en el arcaísmo ${ }^{3}$ heterocrónico en la modernidad. Foucault aclara esta cuestión aludiendo justamente a este arte: "El teatro, que es una heterotopía, hace que sucedan sobre el rectángulo del escenario toda una serie de lugares incompatibles” (Foucault, 1984: 5). Así, mientras que espacios como los museos logran concretar una utopía heterotópica mediante la acumulación de tiempos, las ferias y el teatro lo hacen en forma crónica y efímera (Foucault, 1984: 6).

En este sentido, se podría concebir metafóricamente al santuario del Justo Juez como un escenario teatral, en el que la escena se construye permanentemente con las prácticas de los creyentes, en el aquí y ahora propios de lo efímero en la ejecución del performance, pero con el carácter crónico que le confiere la repetición del ritual y las festividades. El lugar sagrado del Justo Juez, visto como un escenario teatral, parte de ser un espacio abierto a las posibilidades de la actividad humana; en este caso el performance de los ritos al Justo Juez transforma el espacio geométrico en escena viva y concreta.

En una visita de campo, paso por un espacio llamado por los fieles “capilla de velas" del Justo Juez, que en ese momento está solo poblada por velas encendidas para la imagen; cruzo con unas personas que van saliendo de la capilla interior e ingreso a esta.

${ }^{3}$ Desde la óptica de la modernidad, el teatro resulta arcaico, dado el carácter corporal y emotivo de su lenguaje expresivo, en contraposición con la literatura, que es el lenguaje por el que se expresa la razón, lo propio de la civilización (Fischer-Lichte, 2011).

EntreDiversidades. Revista de Ciencias Sociales y Humanidades, Vol. 8, Núm. 2 (17), julio-diciembre 2021. Páginas: 56-76 ISSN-e: 2007-7610. https://doi.org/10.31644/ED.V8.N2.2021.A03 
Por vez primera experimento estar en la iglesia, normalmente llena, sin que haya nadie, por lo que es una excelente oportunidad para observar la entrada de los actores al escenario, su performance o actuación y su salida o mutis. ${ }^{4}$

Empieza la entrada de los actores al escenario... El silencio expectante da importancia y foco a la puerta, que en estos momentos representa el umbral entre ámbitos escénicos.

Luego de un rato de absoluta quietud, dos señoras rezan unos minutos hincadas ante la imagen del Justo Juez; antes de que salgan, llegan otras personas, un par de señoras solas, luego una familia de cinco integrantes. ${ }^{5}$

En este lugar puede observarse la fuerte relación que hay entre los creyentes y el espacio a través del performance. Es interesante el acomodo que toman en la capilla; hay quienes prefieren un rincón discreto y otros que asumen posiciones protagónicas. Así, la forma en que los actores se apropian de su espacio en el escenario del Justo Juez silenciosamente — ya sea en solitario o en bloques grupales - lo ordena y jerarquiza. Esta disposición espacial, sin embargo, es siempre efímera, toda vez que se configura continuamente con las entradas, performances y mutis de los actores; sin embargo, sin mediar regla escrita o dicha, hay siempre un orden en continua recreación determinado por la forma en que las personas se desenvuelven en el espacio con respecto al Justo Juez.

Por otro lado, las características y disposiciones del espacio físico contribuyen también a la formación del lugar, toda vez que provocan además efectos en las prácticas e interacciones de las personas partícipes del escenario. De hecho, durante el tiempo de este estudio la disposición espacial de la iglesia de La Merced sufrió modificaciones importantes que me permitieron observar desde distintos ángulos la relación de los actores con los espacios de los que se apropian y en los que interactúan.

Cuando inicié el trabajo de campo, la iglesia de La Merced estaba cerrada al público, luciendo completamente cercada toda su fachada, como secuela del sismo de septiembre del 2017. El Instituto Nacional de Antropología e Historia (INAH) había inhabilitado el inmueble debido a los daños sufridos; pero al llegar al sitio, un señor de baja estatura, muy moreno, de rostro duro y curtido por el sol y los ańos, me dijo amablemente que a la iglesia se podía entrar siguiendo por la calle (Diego de Mazariegos), que junto a un poste estaba una entrada.

Efectivamente, sobre la calle Diego de Mazariegos existe una entrada pequeña y discreta que conduce a un espacio anexo a la iglesia. Ahí pude ver dos letreros escritos a mano en cartulina con los horarios de apertura y de celebración de las misas en el recinto. Este pasaje desemboca en la "capilla de velas" del Justo Juez. En una de sus paredes se encuentra otra puerta, metálica, con cristal en su parte superior, que conduce directamente al interior. Por ella accedí a la iglesia durante todo el tiempo de su "cierre" oficial.

Una vez dentro, comprobé que estaba como siempre, nutrida de creyentes, en su gran mayoría ejecutando ritos al Justo Juez. A pesar de que se había decretado la clausura terminantemente

\footnotetext{
${ }^{4}$ Estos términos son empleados como parte de la metáfora teatral de este estudio. Tres son las partes primordiales de una actuación teatral: la entrada del actor al escenario, su performance o actuación y su salida o mutis.

${ }^{5}$ Ficha de campo 8 de 15 de febrero de 2018.
}

EntreDiversidades. Revista de Ciencias Sociales y Humanidades, Vol. 8, Núm. 2 (17), julio-diciembre 2021. Páginas: 56-76 ISSN-e: 2007-7610. https://doi.org/10.31644/ED.V8.N2.2021.A03 
por las autoridades federales trascendiendo la autoridad del municipio o incluso de la institución eclesiástica misma - como lo indica el vallado metálico con los sellos del INAH rodeando la fachada_-, en la realidad de las prácticas, aún con algunas modificaciones espaciales y cierta dosis de simulada clandestinidad, estuvo siempre abierta y en constante actividad. Este estado de cosas hace visible la existencia de lugares en los que la lógica cotidiana se rompe, fuera del orden de la razón, los lugares heterotópicos. Desde esta óptica, el santuario del Justo Juez resulta un lugar heterotópico gracias a su singular combinación de espacios, tiempos y prácticas.

\section{El espacio y sus usos}

De forma notoria, la iglesia de La Merced es un lugar polivalente. Está, como su nombre lo indica, dedicada a la virgen de La Merced, patrona del barrio homónimo en el que esta se encuentra, pero es también el santuario del Justo Juez, imagen sagrada venerada más allá de la lógica barrial. Este se conforma a su vez por dos espacios, la capilla interior y la capilla de velas.

\section{Fotografía 1. Capilla del Justo Juez}

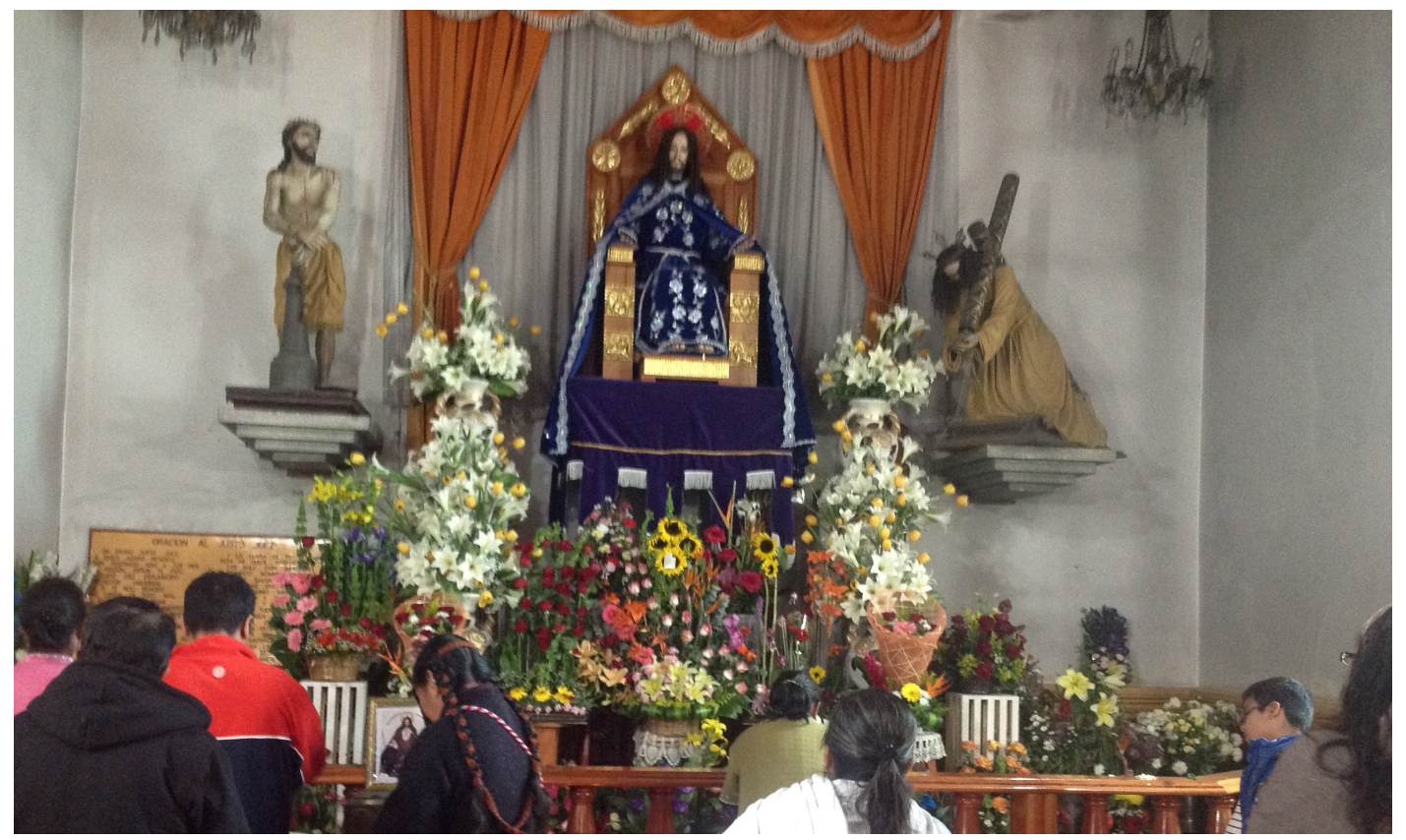

Fuente: Anna María Garza Caligaris, 2013. San Cristóbal de Las Casas, Chiapas, México

La primera es sobria y elegante; el padre Víctor, ${ }^{6}$ capellán de la iglesia, me explicó que, pese a que la imagen patrona de la iglesia y del barrio es la virgen de La Merced, es el Justo Juez el que más contribuye económicamente a la iglesia, razón por la que mandó a remodelar su altar, decorándolo elegantemente con mármol y cedro.

${ }^{6}$ Entrevista al padre Víctor Manuel Anguiano, capellán de la iglesia de La Merced. San Cristóbal de Las Casas. 2 de marzo de 2018.

EntreDiversidades. Revista de Ciencias Sociales y Humanidades, Vol. 8, Núm. 2 (17), julio-diciembre 2021. Páginas: 56-76 ISSN-e: 2007-7610. https://doi.org/10.31644/ED.V8.N2.2021.A03 
El diseño del oratorio interior sigue los cánones católicos propios de las capillas abiertas novohispanas, cuyas dimensiones remiten a cierto tipo de escenario, advierte Óscar Armando García, "a una tipología de casetas o escenarios del teatro medieval" (2015: 99). Esta forma arquitectónica les ha permitido ser espacios de diálogo ritual, cultural y simbólico: "en esta área de intersección cultural, se localizaba el mundo festivo, el conmemorativo, como privilegiado espacio de negociación” (García, 2015: 99). Por tanto, esta misma disposición espacial propicia el uso de las capillas a manera de "escenarios". En el caso de esta investigación, la configuración escénica de esta capilla convierte a la imagen del Justo Juez protagonista en su escenario y, a la vez, público del escenario que se abre frente a él con sus devotos actores.

En contraste con este elegante espacio, la "capilla de velas", así llamada oficialmente, es una construcción simple, de techo bajo, oscura, muy austera, donde predominan las velas y veladoras, constantemente encendidas, acomodadas en tres mesas de concreto dispuestas paralelamente entre sí, frente a un cuadro con la fotografía empastada de la imagen del Justo Juez. Estas dos capillas están unidas por una puerta de estructura metálica y cristal que permanece abierta, permitiendo ver al otro lado, conectándose continuamente; es más, la mayoría de los creyentes usa en mayor o menor medida ambos espacios para llevar a cabo sus ritos. Uno es el escenario del Justo Juez, donde se ejecuta el performance a él; el otro, es el espacio para las ofrendas y las prácticas "no permitidas" por la institución católica.

\section{Fotografía 2. Capilla de velas}

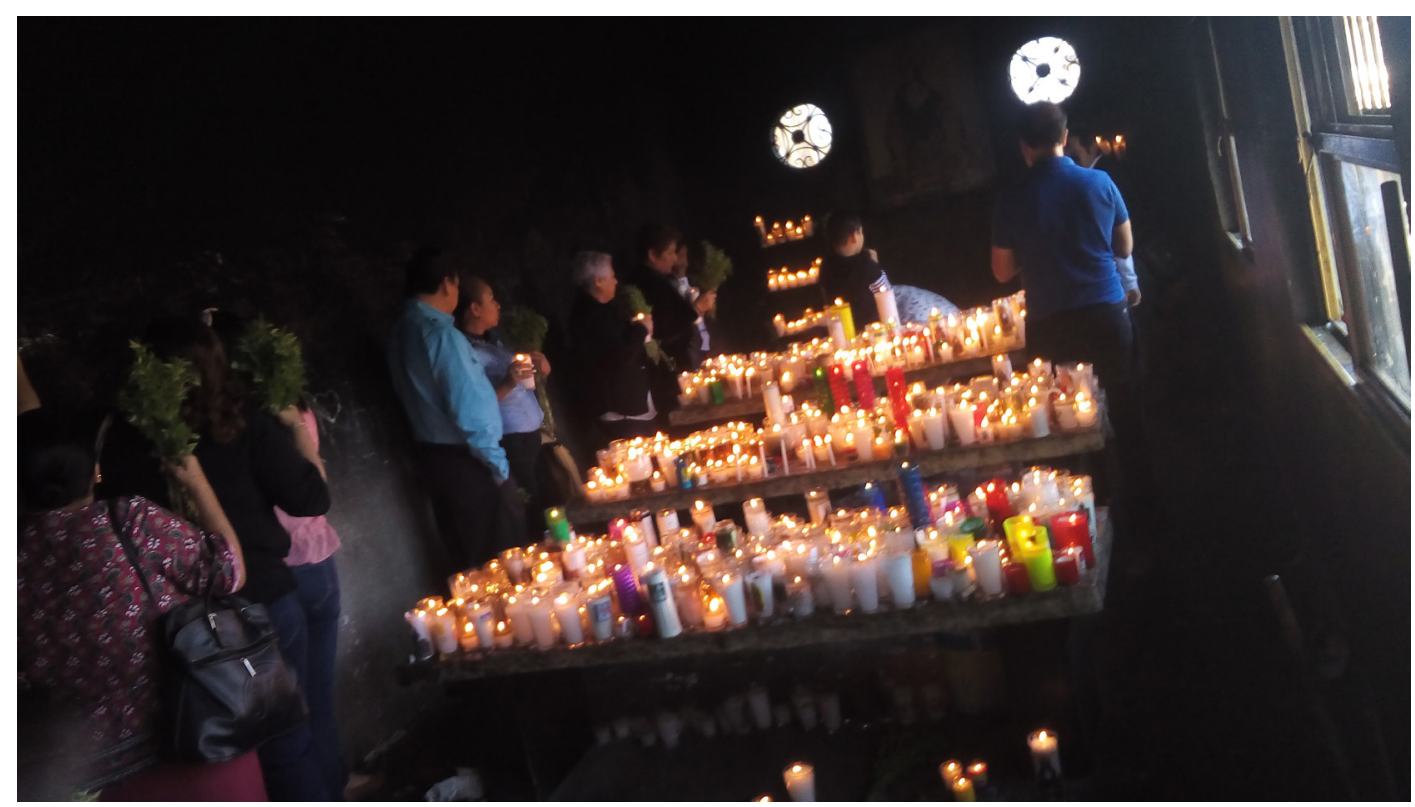

Fuente: Ricardo López Crocker, 2018. San Cristóbal de Las Casas, Chiapas, México. 
Alejandro, sacristán de la iglesia, ${ }^{7}$ me explicó que el humo provocado por velas y veladoras es la causa de que este altar esté separado de la capilla principal. Sin embargo, para el capellán de la iglesia, ${ }^{8}$ la existencia de la capilla de velas en realidad tiene que ver con disimular la usanza indígena para pedir a la divinidad, que incluye velas, fuego, alcohol y animales; él no puede impedir estas prácticas, pero sí disimularlas, dejarlas existir en un sitio especial, de carácter abyecto, donde las anomalías en el culto pueden desarrollarse en su "espacio otro" (Foucault, 1984).

Esta jerarquización ideada por la institución eclesiástica — con un espacio protagónico, visible y elegante, escenario de los performances más "aceptables", con otro semi clandestino, discreto y austero, para los "mal vistos" - fue trastocada durante el periodo de estudio, ya que, al cerrarse la entrada principal, el ingreso a la iglesia era justamente por la "capilla de velas", que perdió durante este tiempo mucho de su carácter abyecto.

En mi observación personal de este espacio, veo que, aunque es evidente la intención del capellán de disimular las prácticas que define como indígenas, a este lugar en realidad acude e interactúa gente de diferentes tipologías sociales, lo que puede observarse en los vestuarios que portan y la lengua en la que rezan; hay quien viste con enagua negra de borrego con largos pelos, reza en tzotzil y sacrifica gallinas, como quien viste con ropa de marcas de prestigio, saco o abrigo, reza en español y ofrenda sus veladoras. En lo que todos aquí coinciden, sin importar su procedencia, es en el hecho de dejar una ofrenda al Justo Juez, ya sea vela o veladora, alcohol o aceite; o hacerlo en tzotzil o espańol.

\section{El lugar y el tiempo. El acontecer desde el aquí y el ahora}

El tiempo es un factor importante en el santuario del Justo Juez. Aunque prácticamente todos los días y a toda hora hay creyentes rezándole, los lunes son especiales, son días en los que el número de creyentes y prácticas es notoriamente mayor.

El lunes es simbólicamente el día del Justo Juez, hecho que guarda una estrecha relación con su origen como imagen advocación de Jesucristo. La fiesta en su honor se celebra el primer lunes de la Semana Santa, lunes Santo, día en que Jesucristo fue aprehendido y juzgado para su posterior crucifixión. Por ello, uno de los ritos más importantes con el Justo Juez es el de "los siete lunes", que consiste en un rezo especial que se ejecuta durante los seis lunes previos a la fiesta, que culmina el séptimo lunes (lunes Santo).

De modo tal que la configuración del lugar y sus performances cambia en relación con el tiempo. En visita de campo:

Acudo a la iglesia de La Merced durante la noche, celebrándose misa. Es el quinto lunes de los siete que enmarcan la celebración del Justo Juez. La misa es convencional, pero sucede en un lugar extra-cotidiano. El tono del sacerdote es serio y solemne; su voz firme y colocada con cierto engolamiento, a la usanza del teatro formal espańol del siglo XIX. Sus ademanes

\footnotetext{
${ }^{7}$ Entrevista a Alejandro Gómez, sacristán de la iglesia de La Merced. San Cristóbal de Las Casas. 23 de abril de 2018.

${ }^{8}$ Entrevista al padre Víctor Manuel Anguiano, capellán de la iglesia de La Merced. San Cristóbal de Las Casas. 2 de marzo de 2018.
}

EntreDiversidades. Revista de Ciencias Sociales y Humanidades, Vol. 8, Núm. 2 (17), julio-diciembre 2021. Páginas: 56-76 ISSN-e: 2007-7610. https://doi.org/10.31644/ED.V8.N2.2021.A03 
son también amplios, diseñados, precisos y presentes, también al estilo de la tradición del teatro formal europeo decimonónico.

Mientras la ceremonia eclesiástica transcurre en forma ortodoxa como en cualquier iglesia católica, las dos capillas del Justo Juez (interior y de velas) se encuentran llenas de creyentes que realizan sus ritos y rezos, sin hacer mayor caso a lo que transcurre tan solo a unos metros y sin separación física de por medio.

La misa continúa, personas salen y entran de las capillas en un ajetreado lunes. La concurrencia en la nave principal ocupa aproximadamente un setenta por ciento de su aforo; en la parte trasera se sitúan tanto feligreses en misa como rezadores y suplicantes que ingresan a la nave para orarle a la imagen escultórica del Justo Juez, que en estas fechas se encuentra en el proscenio 9 del altar principal de la iglesia, junto al sagrario, por ser víspera de su fiesta. Durante la víspera de la gran fiesta del Justo Juez, ${ }^{10}$ la reconfiguración espacial propia de este tiempo se radicaliza. A partir de hoy y hasta el fin de la fiesta, la imagen escultórica del Justo Juez está situada en el centro mismo del altar principal, flanqueado por la Virgen de La Merced, plenamente con el papel protagónico en el espacio.

La misa transcurre y los rezos en las capillas también. Observo cómo en los participantes de la misa el uso y compromiso del cuerpo son mínimos, a pesar de los constantes cambios de posición que la liturgia exige. Mientras, en el altar del Justo Juez el compromiso del cuerpo y el despliegue emotivo tienen una gran intensidad. El hecho de que haya misa interfiere poco con las súplicas de los creyentes del Justo Juez. ${ }^{11}$

Durante la víspera de la gran fiesta del Justo Juez, la condición heterotópica de este lugar sagrado se radicaliza. En todos los espacios de la iglesia hay mucha gente con ramas y palmas para bendecir, pero también con ramas de albahaca y de otras hierbas, usadas también para ramear o "barrer". ${ }^{12}$ De hecho, el elemento ritual primordial en este día son las ramas. En el altar principal, el sacristán con ayuda de otros dos jóvenes atienden a una multitud que se acerca a pedir que les bendigan sus ramas impregnándolas de agua bendita.

El espacio se separa en dos secciones: en la nave principal se encuentra gran cantidad de gente en la bendición de las palmas, un rito que sigue el esquema católico correspondiente al domingo de Ramos; pero en el altar interior del Justo Juez la ritualidad que se desarrolla es otra, aquí la gente está ocupada "barriéndose", ya sea solos, en parejas o en grupos; mientras la

\footnotetext{
${ }^{9}$ Proscenio. Siguiendo con la metáfora teatral, la capilla del Justo Juez es vista como un escenario; desde esta óptica, el proscenio es la parte más frontal del escenario, su límite con respecto al público.

${ }^{10} \mathrm{La}$ víspera de la fiesta del Justo Juez es el domingo de Ramos, día previo al lunes Santo. Ficha de campo 16. 25 de marzo de 2018.

${ }^{11}$ Ficha de campo 14. Iglesia de La Merced, 12 de mayo de 2018.

12 "Barrer" o "barrerse" es la denominación local que se le da a la práctica de la "rameada", llamada en otros lugares de México limpiar o ensalmar. La barrida consiste en pasar en repetidas ocasiones de forma vigorosa una rama (principalmente de albahaca), movimiento que tiene el sentido de limpiar o barrer males o energías negativas acumuladas en el cuerpo.
}

EntreDiversidades. Revista de Ciencias Sociales y Humanidades, Vol. 8, Núm. 2 (17), julio-diciembre 2021. Páginas: 56-76 ISSN-e: 2007-7610. https://doi.org/10.31644/ED.V8.N2.2021.A03 
multitud participa en este frenesí de "barridas", el sacristán ruega repetida e infructuosamente a todos que al terminar se lleven sus ramas para no ensuciar el recinto.

La capilla de velas, por su lado, no muestra alteración en sus prácticas, que consisten primordialmente en rezos y colocación de ofrendas, velas y veladoras.

Los lugares sagrados católicos como este, entonces, son heterocrónicos, pues en su ritualidad amalgaman tiempos. Así, durante la fiesta del Justo Juez, la diversidad y el traslape de los performances que ocurren en este lugar heterotópico se radicalizan, ya que se entrecruzan prácticas institucionales y populares de varios tipos al mismo tiempo, es decir, confluyen, se amalgaman, se abigarran. Esta condición heterotópica entra en progresión hacia su clímax conforme se acerca la fiesta del Justo Juez.

Llega el "mero día" de la fiesta del Justo Juez ${ }^{13}$.

El ambiente en toda la zona de la iglesia de La Merced es totalmente festivo. En el parquecito aledańo a la iglesia está instalada una gran carpa con un altar y sillas para celebrar las misas al aire libre que se llevan a cabo a las 6:00, 8:00, 10:00 y 12:00 horas y son oficiadas por diferentes sacerdotes. La ceremonia estelar es la de las 12:00 horas, presidida por el obispo de San Cristóbal.

Este día, el capellán de la iglesia de La Merced está en fortísimo ajetreo. Sin sotana, ya que funge como organizador de la fiesta, ayudado de algunos feligreses de edad madura y jóvenes catequistas, que son su verdadera fuerza de trabajo.

Se da cita toda la diócesis de San Cristóbal de Las Casas, sacerdotes y obispo, dada la importancia de la fiesta. Este es un día en que la institución eclesiástica se muestra y afirma, en contraposición con la fiesta de la Virgen de La Merced, organizada primordialmente por las juntas de festejos, en la que quienes se afianzan son las autoridades barriales tradicionales. ${ }^{14}$

El culto trasciende el barrio e incluso la ciudad. En esta fecha llega gente de todo Chiapas y de muchas regiones del país que se declaran creyentes del Justo Juez de la iglesia de La Merced en San Cristóbal de Las Casas.

Doña Juana Ordoñez, por ejemplo, vino desde Acayucan, Veracruz; ${ }^{15}$ me comenta que la acompañan su hermana y su cuñada, así como dos de sus hijos, que son los que manejan el carro. Habían planeado venir a esta fiesta desde hace varios años, pero por distintos motivos no les había sido posible. Hoy están muy felices porque pudieron ver al Justo Juez y "sentir su infinito poder y misericordia”.

El cúmulo de gente que acude sin cesar durante todo el día a hacer la visita es impresionante; el constante tumulto hace que el tiempo de estancia en el santuario del Justo Juez en su día sea limitado; el recorrido tiene forma de circuito, con diferentes sitios y filas para la realización de los diferentes rituales. Una fila enorme (nunca menor a los trescientos

\footnotetext{
${ }^{13}$ Ficha de campo 17. 16 de marzo, 2018.

${ }^{14}$ Paniagua (2014: 156-159) plantea que las fiestas patronales dan sentido y estructura a los barrios de San Cristóbal de Las Casas. Estas celebraciones son realizadas por las Juntas de Festejos, que son estructuras organizativas formadas por los habitantes de los barrios para llevar a cabo la fiesta patronal de cada año. Estas juntas controlan todos los aspectos del escenario festivo, constituyéndose como las instituciones más representativas de los barrios.

${ }^{15}$ Charla con la señora Juana Ordoñez, San Cristóbal de Las Casas, 26 de marzo de 2018.
}

EntreDiversidades. Revista de Ciencias Sociales y Humanidades, Vol. 8, Núm. 2 (17), julio-diciembre 2021. Páginas: 56-76 ISSN-e: 2007-7610. https://doi.org/10.31644/ED.V8.N2.2021.A03 
metros de longitud durante al menos ocho horas continuas) es para pasar al altar principal a bendecir ramas o reliquias; otra, casi tan larga como la anterior, es para pasar a ser "barrido" por un "especialista" en el altar de velas.

Es evidente que se realizan varios ritos a la vez: hay colocación de velas, "barridas individuales", en pareja o familiares, "barridas" aplicadas por un "especialista", rezos, cantos, bendición de ramos y reliquias, misas, rosarios, curaciones. Los diversos ritos ocurren al mismo tiempo en el mismo lugar en el que sus tres escenarios lucen pletóricos.

Con la fiesta, el carácter heterotópico del lugar resalta aún más. El espacio entero de la iglesia (nave principal, capilla interior y capilla de velas) está atestado de palmas, ramos y flores que se bendicen, así como de otras hierbas que no se bendicen (como la albahaca y el hinojo), ya que son para "barrer".

Lo más representativo de la ritualidad es sin duda la acción de "barrer" o "barrerse". Se usa albahaca e hinojo para ramear a los niños — sean güeros, morenos, prietos, con vestidos, abrigos, jeans, enaguas de pelo de borrego, hombres, mujeres, niños, adultos, ancianos, indios, ladinos...-. Todos "barren" y son "barridos"; no hay divisiones raciales, de género, de clase, ni edad para ello. En este día todos se someten al rameo que implica la "barrida". De este modo, esta usanza "popular" democratiza, pues todas las tipologías sociales se vuelven efímeramente "una misma" con el Justo Juez.

La festividad del Justo Juez permite comprender en todo su esplendor la enorme complejidad que coexiste en este lugar sagrado. En la iglesia de La Merced se vuelve nítida la división social de San Cristóbal de Las Casas y, a la vez, puede verse la disolución de la misma mediante la fe expresada en el performance del rito.

\section{Entrada, performance y mutis. Las regiones de Goffman y el performance al Justo Juez}

La experiencia humana sucede y se expresa en los espacios, los cuales a su vez se configuran por la actividad, la significación y la interacción de las personas; por lo que puede decirse que los lugares son la manifestación de la experiencia. A este respecto, Vergara (2013: 38) afirma que las personas los crean por su actividad recurrente como individuos, grupos o comunidades, los cuales se encuentran en permanente construcción y configuración a través de la imbricación del uso, las instituciones, las prácticas y las experiencias emo-significativas.

Este planteamiento permite observar cómo las formas posibles de configuración de los lugares resultan prácticamente infinitas, igual que las combinaciones de personas, actividades, historias, relaciones, necesidades, espacios físicos, experiencias, imaginarios e implicaciones emotivas. A la vez, los construye y delimita, lo que permite acotarlos para su estudio como lugares de diversa índole, ya sea de tipo educativo o recreativo, sagrado o profano, etcétera.

El perfil o actividad primordial o recurrente del lugar determina las acciones y modos de actuar legítimos en él. Vergara (2013) plantea que a cada tipo de espacio le corresponden determinadas y características formas de actividad e interacción cotidiana (rutinas), así como

EntreDiversidades. Revista de Ciencias Sociales y Humanidades, Vol. 8, Núm. 2 (17), julio-diciembre 2021. Páginas: 56-76 ISSN-e: 2007-7610. https://doi.org/10.31644/ED.V8.N2.2021.A03 
rituales específicos que se desarrollan en estos espacios acotados, y estar en ellos determina a actuar de esa determinada forma. Por tanto, en el lugar sucede lo cotidiano o rutinario y lo extracotidiano o ritual (Barba, 1992).

La interacción humana (cotidiana o extra-cotidiana) sucede en el sitio, lo que determina su carácter; Vergara explica esta relación: "[...] la forma permanente y principal de la interacción expresa el carácter del lugar, que puede devenir en sagrado o profano, privado o público, laboral o residencial, etcétera, definiendo una especial interrelación espacial y temporal que diferencia y une, concentra y/o dispersa" (2013: 84).

Esta perspectiva hace posible articular el lugar con elementos teatrales de análisis, ya que la actividad humana que sucede en el espacio produce, en palabras de este autor: "[...] el ritmo, la parsimonia o la velocidad, las sonoridades y silencios — sus secuencias y alternancias—, expresan un tipo de actuación que está determinada por la naturaleza de las interacciones que el lugar impele, estimula, condiciona o determina" (2013: 85).

Este planteamiento se puede vincular con la propuesta de Erving Goffman, autor que analiza el mundo social desde una perspectiva escénica. Goffman (1959) plantea que existen dos ámbitos de acción humana a los que llama regiones, una anterior y una posterior. Cada una "puede ser definida como todo lugar limitado, hasta cierto punto, por barreras antepuestas a la percepción" (Goffman, 1959: 117). Se trata de una metáfora escénica mediante la cual argumenta que todos actuamos nuestro personaje ${ }^{16}$ (máscara, persona) de acuerdo con el ámbito, la intención y la o las personas con las que se interactúe, y que toda actuación requiere de dos lugares complementarios: la región anterior sería el "escenario" de la actuación y la región posterior el "trasfondo escénico"; en el trasfondo escénico se preparan los elementos y el personaje que aparecerán en el escenario.

Las regiones de Goffman permiten observar las fragmentaciones que presenta el espacio, a través de las diferentes prácticas que suceden en las interacciones sociales por medio de las cuales las personas se construyen como sujeto-actor-personaje en los diferentes ambientes del lugar, de acuerdo con su naturaleza y significación.

Esta distinción básica de los ámbitos de la actuación humana en la interacción cara a cara permite articular el lugar con la teatralidad ${ }^{17}$ mediante la perspectiva de la antropología teatral ${ }^{18}$ de Eugenio Barba, que tiene en la noción de extra-cotidianidad una de sus bases. El autor argumenta que en una situación de representación escénica existe un manejo del cuerpo diferente al cotidiano, lo que conduce también a distinguir dos ámbitos: un manejo o técnica cotidiana del cuerpo y un manejo o técnica extra-cotidiana.

\footnotetext{
${ }^{16}$ Goffman (1959) emplea la metáfora teatral para explicar que todos "actuamos" en la presentación de nuestra persona (máscara, personaje) en la vida cotidiana; esta presentación, en distintos ámbitos y ante diferentes personas, nos obliga a modificar nuestra "actuación" para ser convincentes y pertinentes en cada escenario de la vida. Para explicar estos cambios de ámbito de actuación, Goffman emplea el término de "regiones".

${ }^{17}$ Las nociones de teatralidad se refieren a las propias de la puesta en escena, no de la dramaturgia.

${ }^{18}$ Eugenio Barba define a la antropología teatral como: "el estudio del comportamiento del ser humano a nivel biológico y sociocultural en una situación de representación” (Barba, 1992: 17).
}

EntreDiversidades. Revista de Ciencias Sociales y Humanidades, Vol. 8, Núm. 2 (17), julio-diciembre 2021. Páginas: 56-76 ISSN-e: 2007-7610. https://doi.org/10.31644/ED.V8.N2.2021.A03 
Las técnicas cotidianas son más funcionales cuanto menos se piense en ellas. Nos movemos, besamos, asentimos con gestos que creemos "naturales" y que en cambio son determinados culturalmente. El primer paso para descubrir cuáles pueden ser los principios del bios escénico del actor, su "vida", consiste en comprender que a las técnicas cotidianas se contraponen técnicas extra-cotidianas que no respetan los condicionamientos habituales del cuerpo (Barba, 1992: $34-35)$.

La observación de las prácticas performativas de los creyentes del Justo Juez en sus capillas de la iglesia de La Merced hace posible advertir el tránsito que realiza la persona entre distintos ámbitos de actuación. Deja ver detalles de la construcción de su máscara cotidiana (manifestación perceptible de su persona en la interacción diaria) con la deconstrucción de la misma cuando se abandona para encarnar otra, la extra-cotidiana, que aparece en el momento límite del rezo de súplica, la súplica vital al otro, al ser numinoso ${ }^{19}$ personificado en el Justo Juez.

El lugar, entonces, presenta fragmentaciones que lo complejizan. Así, los ámbitos en los que se divide el santuario del Justo Juez están estrechamente relacionados con las nociones de cotidianidad y extra-cotidianidad; la región posterior es para los creyentes la propia de la cotidianidad, la de la máscara presentada en la vida cotidiana; la región anterior, el escenario del Justo Juez, es para el personaje capaz de ingresar a la esfera de lo sagrado para ejecutar un performance con la suficiente capacidad expresiva para conmover a la deidad. Por tanto, las regiones suceden y se manifiestan en el cuerpo de las personas, en la forma de encarnar sus personajes y de expresar u ocultar el movimiento emocional que sucede en su interior.

Las clasificaciones sociales (raciales, genéricas, etáreas) residen en la máscara de la vida cotidiana y son parte fundamental de la interacción cotidiana de las personas; el sentido religioso no suprime las de la cotidianidad, sin embargo, cuando el creyente (hombre, mujer, joven, viejo, indio o ladino) ingresa a la esfera extra-cotidiana de lo sagrado en la ejecución del rito, cuando logra acceder al territorio de la hierofanía, ${ }^{20}$ son diluídas por el paso a un estado mental, corporal y emotivo extra-cotidiano de trascendencia, un momento susceptible de ser observado como estético.

\footnotetext{
${ }^{19}$ Lo numinoso, deriva del latín numen: divinidad, majestad divina, dios; se refiere, pues, a las deidades y sus deseos, su voluntad, su poder. Se aplica también a la inspiración que siente el artista y que estimula la creación de obras de arte; se suele representar personificada, por ejemplo, con las musas. Rudolph Otto utilizó la palabra numen para describir al ser sagrado supremo al quien todas las religiones tienden a intentar conocer, el núcleo esencial de sentido (Otto, 1965: 27).

${ }^{20}$ La hierofanía es la experiencia que surge ante lo numinoso. Para Otto, ante lo numinoso surge una emoción fundamental que se experimenta en la experiencia sagrada, a la que define como "temblar en emoción" (Otto, 1965: 17-18). Este término metafórico, intenta describir un fenómeno inexplicable racionalmente; según Otto el misterio de lo numinoso es que contiene a la vez la dimensión de lo sobrecogedor, aterrador y la de lo fascinante, encantador (1965: 38-39); dichas dimensiones son las que llevan a la aspiración de tener experiencias hierofánicas. Vasconi explica que en la experiencia hierofánica, lo habitual se convierte en otra cosa sin dejar de ser lo que es en la cotidianidad, "el hombre religioso ańade un nuevo sentido habitual del mundo, pero no suprime su sentido primero" (Vasconi, 2015: 96).
}

EntreDiversidades. Revista de Ciencias Sociales y Humanidades, Vol. 8, Núm. 2 (17), julio-diciembre 2021. Páginas: 56-76 ISSN-e: 2007-7610. https://doi.org/10.31644/ED.V8.N2.2021.A03 
Este tránsito entre las regiones configura el lugar y es evidente a pesar de no ser visible, como lo experimenté en mi trabajo de campo. ${ }^{21}$

Entro a la capilla interior, lo hago junto a una mujer joven (de veintitantos años) que sonríe y me cede el paso, luego entra sin más. La joven es de mediana estatura, complexión delgada, cabello negro ligeramente ondulado y tez morena clara; viste de pantalón de mezclilla, tenis y sudadera deportiva. Se coloca frente al Justo Juez, se persigna y se acomoda hincada en posición de rezo; ${ }^{22}$ una vez que ha fijado su postura corporal, su emoción brota como accionada por un resorte que la hace estallar con gran intensidad. A pesar de la fuerte emotividad manifestada en su cuerpo presa del llanto, su voz apenas se oye, murmura su pena en un volumen pianísimo. Luego de unos minutos, se incorpora y va a situarse frente a la imagen escultórica del Justo Juez donde retoma su posición de rezo.

A ese lugar —en el que no había nadie hasta que la joven de mezclilla se situó en él, frente a la imagen - se acerca a rezar una señora de edad madura, es de piel morena, curtida por el sol, viste con enagua negra. Entra junto a un hombre, al parecer su marido, y se sitúan justo al lado de la joven de mezclilla. Desde mi ubicación los tres me dan parcialmente la espalda. Luego de un rato, se escucha el murmullo fuerte de una súplica, no se logra distinguir la lengua en que se invoca, las palabras brotan en un sonsonete intenso, demasiado cargado de emoción como para distinguir lo que se dice. El tono relativamente grave de la voz y la profundidad desgarrada del intenso sufrimiento expresado sonoramente me hacen pensar que es la señora madura la que reza; pero rato después, esta se va mientras el rezo continúa: ¡quien llena el espacio con su voz es la joven de mezclilla!

Para ejecutar el performance al Justo Juez y apropiarse del espacio entero con la voz y la emoción expresadas no hace falta un vestuario ni un idioma en particular. Las apariencias y prejuicios propias de las clasificaciones que atribuimos a las personas en la cotidianidad se diluyen efímeramente ante actos como este, en que un rezo que podría parecer de una señora mayor de origen indígena y campesino puede resultar ser el de una joven mestiza urbana; o, por el contrario, el prejuicio podría residir en clasificar a alguien por la vestimenta, la que más bien puede caracterizar una de sus máscaras, una que ante el Justo Juez se abandona para ejecutar un performance capaz de conmoverlo.

$\mathrm{Al}$ traspasar la puerta que permite ingresar a las capillas del Justo Juez, se cruza un umbral entre dos dimensiones del mismo lugar, en las que con tonos distintos se penetra a donde el ser humano se conecta profundamente con su interior más resguardado, para focalizarlo y volcarlo hacia afuera, hacia el Justo Juez.

El lugar impone su manera de ingreso; a diferencia de los ámbitos cotidianos, en los que la gente puede descansar, platicar, dormir, hablar por teléfono o "echar novio", ante el escenario del

\footnotetext{
${ }^{21}$ Ficha de campo 7. Visita del 13 de febrero de 2018.

${ }^{22}$ Para este estudio, se usará el término "posición de rezo" para designar a una posición básica que utiliza la gente para rezar: de rodillas, con las manos juntas a la altura del pecho. Esta posición base tiene múltiples variantes en referencia al performance de los ejecutantes.
}

EntreDiversidades. Revista de Ciencias Sociales y Humanidades, Vol. 8, Núm. 2 (17), julio-diciembre 2021. Páginas: 56-76 ISSN-e: 2007-7610. https://doi.org/10.31644/ED.V8.N2.2021.A03 
Justo Juez los actores tienen que cambiar de región para ingresar al ámbito de lo sagrado. Este lugar impone sin regla escrita su manera de ingreso, toda vez que sus fronteras se definen por las prácticas y los performances.

Para dirigir la súplica al Justo Juez hay que situarse en un determinado estado mental, corporal y emotivo que permita el ingreso a la esfera de lo sagrado, en la que habita el ser numinoso con el que se va a interactuar. Solo se es parte del lugar sagrado cuando se está en la condición adecuada, que no permite la cotidianidad. En trabajo de campo: ${ }^{23}$

Observo a un hombre joven rezando en la capilla interior; está hincado en posición de rezo, ora. De pronto, suena su celular, lo contesta; habla hincado, pero la posición no corresponde al territorio de la cotidianidad de la llamada, se vuelve incómoda y ridícula, por lo que mejor opta por pararse; termina la llamada y retoma brevemente su rezo de pie y se va.

Las dos regiones rompieron sus convenciones de trasfondo escénico y de escenario con la llamada telefónica; sobre todo porque al contestar salió abruptamente del ámbito extra-cotidiano propio de la esfera de lo sagrado, diluyendo su propio performance. Esto se debe a que lo sagrado representa una convención fruto de la voluntad. Vasconi explica cómo forma parte de una esfera particular, con una intencionalidad autónoma, cita a Eliade:

Pero algo es al menos obvio: las obras de arte, así como los "datos religiosos", tienen una forma de ser que les es propia, existen en su propio plano de referencia, en su universo particular. El hecho de que este universo físico no sea el de la experiencia inmediata no significa que no sea real" (Eliade, citado por Vasconi, 2015: 91).

Como explica el autor, las obras de arte existen primordialmente en su propio marco de referencia, no tienen sentido utilitario en sí; igual sucede con lo sagrado. En el arte algo que el sentido común podría considerar como horrible o negativo puede ser transformado en un hecho estético desde su propia referencialidad artística. Lo extra-cotidianamente bello del arte no necesariamente coincide con la vida cotidiana, incluso puede llegar a contradecirla, dice Vasconi, y continúa: "Las actitudes existenciales (cotidiana, estética, científica, religiosa) se constituyen en relación con mundos diferentes y, en principio, independientes" (2015: 92). Por tanto, la diversidad está presente en los ámbitos del existir por los que unos y otros transitamos; de ahí que las experiencias estéticas y religiosas, aunque no son parte de la realidad "real" (tangible, utilitaria), existen si se accede a su esfera particular. De esta manera, el ingreso al ámbito de lo sagrado tiene que ver con la intencionalidad y la emoción religiosa, "las hierofanías aparecen siempre acompañadas de una intención particular, toda vez que implican la interacción con un objeto irracional que no puede ser aprehendido desde la razón. Esta particular relación con el ser numinoso es obra de la emoción religiosa" (Vasconi, 2015: 93). Así, lo sagrado se revela ante una determinada emoción; la aprehensión del mundo es sensorial y corporal, toda vez que desde el cuerpo se participa del mundo sensible.

${ }^{23}$ Ficha de campo 4. Visita del 25 de enero del 2018. Capilla interior.

EntreDiversidades. Revista de Ciencias Sociales y Humanidades, Vol. 8, Núm. 2 (17), julio-diciembre 2021. Páginas: 56-76 ISSN-e: 2007-7610. https://doi.org/10.31644/ED.V8.N2.2021.A03 
El ingreso a la esfera extra-cotidiana de lo sagrado no siempre es inmediato, ya que conlleva sustraerse del ruido o dispersión mental de la cotidianidad.

Ante el Justo Juez, ${ }^{24}$ observo a un hombre solo, en apariencia cuarentón. Se sitúa en la capilla interior, se hinca; permanece así varios minutos, con los brazos laxos recargados en sus piernas, como si simplemente estuviera reflexionando o meditando. Luego de un lapso aproximado de quince minutos, su cuerpo empieza a tomar un tono más presente, sus manos se entrecruzan y empieza a rezar. Su tono corporal se transforma haciéndose presente con el tronco plenamente erguido y sus brazos vibrando al compás del sonsonete de su oración. El ingreso a la extra-cotidianidad no siempre es inmediato, y sin él no se accede a la esfera del Justo Juez.

Hay una fuerte correlación entre el modo de dirigirse - la vivencia intencional expresada en el performance - y el objeto — ser numinoso — que se hace presente para quienes ingresan al ámbito sagrado. Sagrado y profano son dos esferas particulares que se abren ante "dos modos de ser en el mundo" (Eliade, en Vasconi, 2015: 94). El Justo Juez es el lugar donde los dos ámbitos se encuentran; el ser ingresa del ámbito profano, con sus prácticas cotidianas encarnadas, para introducirse a la esfera sagrada.

Veo entrar a la capilla del Justo Juez a un hombre vestido al estilo ranchero, este hombre, al que calculo alrededor de los cincuenta años, es alto (entre 1.75 y 1.80m.), delgado y fuerte; su estilo es impecable, con botas picudas, mezclilla, sombrero y una vistosa camisa de corte y motivos equinos, en colores negro y naranja. El tipo presenta la imagen de un estrambótico cowboy chiapaneco; se nota inmediatamente que es un hombre duro, de campo, rudo, así lo reflejan el tamaño y rugosidad de sus manos, además de la dureza de sus rasgos en su rostro curtido por el sol.

Luego de una breve santiguada, el hombre empieza a orar, lo hace con gran humildad, hincado en posición de rezo, con la cabeza gacha; sus manos expresan poderosamente su sentir; reza desesperado con ambas manos en su cara, como sosteniendo sus mejillas y, con ellas, su alma palpitante de dolor. Luego, alterna sus manos poniéndolas en su pecho; son manos que contienen a su ser maltrecho, el cual ciñe contra sí mientras implora derramando sus lágrimas ante el Justo Juez.

Trae una bolsa negra de plástico con elementos rituales guardados en ella. Saca una botella de plástico y una lata, ambas con líquido; las sitúa en el proscenio del altar interior y continúa su rezo, ahora postrado en posición de súplica. ${ }^{25}$

\footnotetext{
${ }^{24}$ Ficha de campo 6. Visita del 12 de febrero de 2018. Iglesia de La Merced, capilla interior.

${ }^{25} \mathrm{Al}$ igual que con la "posición de rezo", la "posición de súplica" es otra postura encontrada en el santuario del Justo Juez. Básicamente, la persona se pone de rodillas con las nalgas en los talones, echando el torso hacia adelante y la cabeza hacia el frente y abajo hasta tocar el piso. Esta posición base presenta también variantes en virtud de los ejecutantes.
}

EntreDiversidades. Revista de Ciencias Sociales y Humanidades, Vol. 8, Núm. 2 (17), julio-diciembre 2021. Páginas: 56-76 ISSN-e: 2007-7610. https://doi.org/10.31644/ED.V8.N2.2021.A03 
Durante todo el rito, las dos botellas permanecen en el proscenio, como ofrecidas a la deidad. Luego, guarda sus botellas en la bolsa, se pone de pie, va a un recipiente del aceite, ${ }^{26}$ toma un poco y se lo unta en la frente, las sienes, la base del cráneo, la nuca, mientras sigue rezando. Termina y sale a la capilla exterior, prende su vela, reza un rato más y se va. Su rito dura más de cuarenta minutos.

Lo sigo. Al incorporarse para dirigirse hacia la salida, camina despacio, con un tono totalmente relajado, como vacío; al llegar al umbral de la salida, se detiene un momento, revisa traer la camisa bien fajada, como corresponde a lo impecable de su vestuario. Una vez recompuesto, sale; ya en la calle, su andar se transforma, vuelve a ser nuevamente enérgico, sacando el pecho dando amplitud al movimiento de vaivén de los brazos, camina con la mirada altiva y el peso bien plantado en el piso, como todo un verdadero ranchero de Los Altos de Chiapas. ${ }^{27}$

Pude observar en varias ocasiones a este hombre, fui testigo de sus transformaciones ante el Justo Juez. En la cotidianidad porta una máscara construida para corresponder al estereotipo del hombre ranchero; con los atavíos (sombrero y pantalón vaqueros, cinturón con prominente hebilla metálica, camisa con motivos ecuestres), la actitud corporal y la calidad de movimiento correspondientes a un hombre rudo y dominante. Pero muestra su antítesis en el momento extra-cotidiano y límite de la imploración, en el que su público deja de ser el de siempre, ya sean los compañeros y amigos con los que trata, ya sea en su casa, donde probablemente es el padre de familia. En el escenario del Justo Juez nos muestra su lado débil, frágil, desamparado; en ese lugar heterotópico él puede hacer brotar lo que su interior oculta a los demás: su dolor, su desesperación.

El personaje cotidiano se queda afuera, en este escenario el que importa es el Justo Juez, el único que puede ayudarlo si es capaz de conmoverlo y convencerlo con su súplica. El performance de este hombre muestra momentos en que los estereotipos sociales pasan a un segundo plano, diluyéndose efímeramente para mostrarse como un ser humano en esencia ante la deidad.

En otra ocasión en que pude observar este hombre, ${ }^{28}$ entró a ejecutar su rezo a la capilla junto a un joven cuyo rostro se le parece mucho, que viste a su estilo y trata de comportarse como él; probablemente es su hijo.

El porte ranchero del joven es aún un tanto endeble, ya que, debido a su corta edad, su personaje cotidiano está aún en construcción; se le ve tratando de emular en todo al hombre mayor, sobre todo en la actitud corporal. A la hora de iniciar la súplica es notorio que el muchacho se apena, su cuerpo se contrae con incomodidad, no logra quedarse quieto y voltea discretamente a los lados para ver si lo observan; luego de un breve lapso no aguanta

\footnotetext{
${ }^{26} \mathrm{El}$ aceite referido es el que se utiliza normalmente como humectante de la piel, principalmente de los bebés. En la capilla del Justo Juez hay una pileta con aceite bendito de uso ritual.

${ }^{27}$ Ficha de campo 12. Visita del 5 de marzo de 2018. Iglesia de La Merced, capilla interior.

${ }^{28}$ Ficha de campo 15. Visita del 19 de marzo de 2018. Iglesia de La Merced, capilla interior. Sexto lunes del Justo Juez.
}

EntreDiversidades. Revista de Ciencias Sociales y Humanidades, Vol. 8, Núm. 2 (17), julio-diciembre 2021. Páginas: 56-76 ISSN-e: 2007-7610. https://doi.org/10.31644/ED.V8.N2.2021.A03 
más, se incorpora y se sitúa en una banca de la nave principal de la iglesia, donde espera a que el hombre mayor termine con su rito.

Este realiza una súplica muy parecida a la que ya había presenciado, a diferencia de que en esta ocasión se despoja del sombrero y se hacen evidentes sus abundantes canas, mismas que me confirman que debe tener más de cincuenta años. Trae, como en la anterior ocasión, una bolsa negra con su utilería, que consiste nuevamente en dos frascos con líquido, mismos que coloca en el proscenio del altar interior. Su compromiso emotivo es impresionante; este rudo hombre saca su alma del interior de su ser y la vuelca ante la deidad cual corazón en sacrificio.

Al entablar diálogo con él, me dijo que estaba haciendo los siete lunes para que el Justo Juez le concediera un milagro muy importante, ya que él le tiene mucha fe. El particular performance de este hombre - con sus marcadas características de una tipología social de hombre maduro ranchero, altivo y dominante, que puede transformarse en un ser sufriente, desvalido, humilde y plañidero, características generalmente atribuibles a personas débiles o desprotegidas, tales como ciertos estereotipos de lo femenino- aporta una particular configuración a este lugar sagrado, ya que permite observar el ingreso de la persona a la esfera hierofánica. Este tránsito posibilita ver que la capilla del Justo Juez se transforme en un escenario, donde el espectador privilegiado es el ser numinoso, capaz de ayudar en cualquier trance desesperado, siempre y cuando se le convenza.

Los lugares presentan fragmentaciones y fronteras, como las que configuran las regiones y ámbitos, anterior y posterior, cotidiano y extra-cotidiano, pero entre estas existen también los intersticios o momentos intersticiales, en los que las propias regiones y ámbitos pueden fundirse, mostrando su real imbricación en el espacio. Esto se advierte en la capilla del Justo Juez, donde he podido localizar estos momentos en que la cotidianidad y la extra-cotidianidad conviven haciendo gala de una gran diversidad de expresiones.

Observo en el altar de velas un rito colectivo familiar con el Justo Juez, con una oficiante que conoce el rezo (aunque se ayuda de un escrito) y la secuencia de acciones que deben realizarse. El carácter familiar del rito puede percibirse, además de en las características físicas de los participantes, en el trato entre ellos, muy en confianza y cotidiano, en el que no faltan las bromas y risas, contenidas por la supuesta solemnidad del acto. ${ }^{29}$

A pesar de las largas y relativamente complicadas partituras de acciones implicadas en el rito, nunca se rompió del todo la cotidianidad propia del relajo, quedando así en el intersticio de los ámbitos cotidiano y extra-cotidiano, familiar y escénico.

${ }^{29}$ Ficha de campo 13. Visita del 12 de marzo de 2018. Quinto lunes del Justo Juez.

EntreDiversidades. Revista de Ciencias Sociales y Humanidades, Vol. 8, Núm. 2 (17), julio-diciembre 2021. Páginas: 56-76 ISSN-e: 2007-7610. https://doi.org/10.31644/ED.V8.N2.2021.A03 
Otra zona intersticial se encuentra en la manera en que el habitus corporal ${ }^{30}$ cotidiano incide en el performance extra-cotidiano; encontré este comportamiento ante el Justo Juez observando a una señora mayor: ${ }^{31}$

[...] aparenta tener más de sesenta años y viste enagua negra de pelo de borrego. Al principio, reza sola al frente de la nave principal, con referencia al Justo Juez; hincada, con las nalgas en los talones y el tronco erguido. Su voz es sonora y fuerte, de un tono grave, reza en semi staccato; ${ }^{32}$ lo hace por varios minutos.

Luego, empieza a hacer una serie de reverencias; estas se ejecutan a un ritmo constante, sin llegar a poner totalmente la frente en el piso; realiza sus movimientos con precisión, ritmo y vigor, acompanándolos de la oración. Su presencia es notable y se expresa sobre todo en el trabajo del tronco, al formar un eje perfecto en juego de contrarios, con vectores entre la cabeza y el coxis.

Es notable una técnica corporal de uso de la zona media del cuerpo, la cual puede provenir de la cotidianidad posiblemente campesina de la señora al cargar niños o leña en la espalda; el trabajo entrena el tronco para un uso óptimo. Esta técnica corporal cotidiana se traslada e incide en la ejecución extra-cotidiana, mostrando otros usos y posibilidades del cuerpo más allá de lo puramente utilitario. También, hace visible cómo la encarnación de la vida cotidiana construye nuestro cuerpo, reflejándose e incidiendo en todas las esferas de actividad humana.

\section{Reflexiones finales}

La articulación teórica de las nociones de heterotopía, lugar antropológico, las regiones de la actuación en la vida cotidiana y extra-cotidianidad resulta de utilidad para observar aspectos de los fenómenos performativos en su acontecer desde su dimensión espacial.

A través de la distinción entre los ámbitos cotidiano y extra-cotidiano, me fue posible observar la generación de este lugar sagrado, en el que existe una dilución efímera de las clasificaciones sociales cotidianas a través de las prácticas performativas ejecutadas por los creyentes.

Las prácticas de religiosidad que la gente realiza trascendiendo la ritualidad católica institucional construyen este lugar, y con su teatralidad lo configuran como sagrado y estético.

\footnotetext{
${ }^{30}$ Mauss (1936) plantea que para realizar una actividad física concreta (como la natación o la carrera) existen diferentes formas de hacerlo, que varían con relación al lugar y el tiempo. Estas "formas" se enseñan y aprenden, por lo que hay una enseñanza técnica; una técnica corporal concreta. Cada técnica tiene su forma y cada sociedad posee las suyas propias. Esto no solo aplica a actividades físicas concretas, sino también al desenvolvimiento del cuerpo en la cotidianidad, por ejemplo, en las formas de caminar, de tener las manos en reposo, de comer. No existe una "forma natural" en un adulto (Mauss, 1936: 338-341). El autor da a esta "forma" el término "habitus", que es una noción que implica hábito y técnica, ya que "obedece a procesos biológicos, psicológicos y sociales" (1936: 341).

${ }^{31}$ Ficha de campo 9. Visita del 9 de febrero de 2018. Capilla interior.

${ }^{32}$ Semi staccato. En italiano, staccato es "despegado, destacado". En notación musical es un signo de articulación que indica que una serie de notas muy breves sean articuladas por separado; el prefijo semi se utiliza para indicar una atenuación del efecto en la interpretación.
}

EntreDiversidades. Revista de Ciencias Sociales y Humanidades, Vol. 8, Núm. 2 (17), julio-diciembre 2021. Páginas: 56-76 ISSN-e: 2007-7610. https://doi.org/10.31644/ED.V8.N2.2021.A03 
Su particular condición y sus prácticas muestran la estrecha relación que el ser humano establece con su dimensión estética a través de la religiosidad y sus manifestaciones. Así, la teatralidad se plantea como una perspectiva útil para observar fenómenos complejos desde las prácticas y la dimensión emotiva de las personas.

\section{Bibliografía citada}

Barba, Eugenio (1992). La canoa de papel. Tratado de Antropología Teatral. México: Escenología. Brook, Peter (1968). El espacio vacío. Madrid, España: Península.

Fischer-Lichte, Erika (2014). Estética de lo performativo. 2a edición. Madrid, España: Abada editores.

Foucault, Michel (1984). “Topologías”. Fractal [en línea], Año 12, 13 (48), enero-marzo, pp. 39-62. Disponible en: https://www.mxfractal.org/RevistaFractal48MichelFoucault. html (Consultado el 22 de junio de 2018).

García, Óscar Armando (2015). Capilla abierta, de la prédica a la escenificación. Ciudad de México, México: Consejo Nacional para la Cultura y las Artes, Instituto Nacional de Bellas Artes.

Goffman, Erving (1959). La presentación de la persona en la vida cotidiana. Buenos Aires, Argentina: Amorrortu editores.

León Cázares, María del Carmen (2004). Reforma o extinción. Un siglo de adaptaciones de la Orden de Nuestra Señora de La Merced en Nueva España. México, D.F., México: Universidad Nacional Autónoma de México.

Mauss, Marcel (1936). “Técnicas y movimientos corporales”. Sociología y antropología. Madrid, España: Tecnos, pp. 336-355.

Otto, Rudolf (1965). Lo santo: lo racionaly lo irracional en la idea de Dios. Buenos Aires, Argentina: Editorial Selecta, Revista de Occidente.

Paniagua, Jorge (2014). Diversidad urbana y ciudad. Una perspectiva antropológica. San Cristóbal de Las Casas, Chiapas, México: Instituto de Estudios Indígenas, Universidad Autónoma de Chiapas.

Vasconi, Rubén (2015). "Religión y fenomenología: hacia una comprensión del fenómeno religioso". Religión: Estudios antropológicos sobre sus problemáticas. Buenos Aires, Argentina: Biblos, pp. 88-97

Vergara, Abilio (2013). Etnografía de los lugares: una guía antropológica para estudiar su concreta complejidad. México, D.F., México: Navarra.

EntreDiversidades. Revista de Ciencias Sociales y Humanidades, Vol. 8, Núm. 2 (17), julio-diciembre 2021. Páginas: 56-76 ISSN-e: 2007-7610. https://doi.org/10.31644/ED.V8.N2.2021.A03 


\section{Entrevistas etnográficas}

López Crocker, Ricardo (2018). Entrevista semi estructurada a Victor Manuel Anguiano, capellán de la iglesia de La Merced de San Cristóbal de Las Casas, Chiapas [comunicación personal]. 2 de marzo de 2018.

López Crocker, Ricardo (2018). Entrevista semi estructurada a Alejandro Gómez, sacristán de la iglesia de La Merced de San Cristóbal de Las Casas, Chiapas [comunicación personal]. 23 de abril de 2018.

López Crocker, Ricardo (2018). Charla con Juana Ordoñez, devota del Justo Juez de San Cristóbal de Las Casas, Chiapas [comunicación personal]. 26 de marzo de 2018. 